\title{
Effect of increased pressure on tracheal ciliary beat frequency
}

\author{
J.H. Calvet* ${ }^{+}$, F. Verra* ${ }^{\#}$ J. Maleine*, M.C. Millepied ${ }^{\star}$, A. Harf ${ }^{+}$, E. Escudier ${ }^{+\S}$
}

Effect of increased pressure on tracheal ciliary beat frequency. J.H. Calvet, F. Verra, J.Maleine, M.C. Millepied, A. Harf, E. Escudier. CERS Journals Ltd 1999.

ABSTRACT: Effects of increased ambient pressure on mucociliary clearance have been poorly investigated.

The effects of increasing pressures on ciliary beat frequency (CBF) of guinea-pig tracheal rings were studied in vitro.

Increased pressures of 25 and $100 \mathrm{kPa}$ induced a significant and equivalent enhancement of CBF from $30 \mathrm{~min}$ after the pressure increase. The increase in CBF observed after a pressure increase of $50 \mathrm{kPa}$ (inspiratory oxygen fraction $=21 \%$ ), was significantly greater than that observed with an equivalent oxygen tension at atmospheric pressure, i.e. with a gas mixture containing $30 \%$ oxygen. Addition of $N^{\mathrm{G}}$-nitroL-arginine methylester (L-NAME) inhibited the enhancement in CBF observed after the $25 \mathrm{kPa}$ pressure increase. Addition of L-arginine reversed the effect of L-NAME.

These results demonstrate that a pressure increase applied to tracheal rings, in vitro, induces an enhancement of ciliary beat frequency and that generation of nitric oxide may be involved in this ciliary stimulation.

Eur Respir J 1999; 14: 80-83.
*Labratoire de Physiopathologie Respiratoire, Centre d'Etudes du Bouchet, Vert-le Petit, France. ${ }^{+}$Physiopathologie et Thérapeutique Respiratoires, INSERM, Créteil, France. "Division de Pneumonologia, Hospital M. Ferrer, Universidad de Buenos Aires, Argentina. 'Service d'Anatomopathologie, Hôpital Intercommunal, Créteil, France. ${ }^{\S}$ Service d'Histologie, Groupe Hospitalier Pitié-Salpetriére, Paris, France.

Correspondence: J.H. Calvet, Laboratoire de Physiopathologie Respiratoire, Centre d'Etudes du Bouchet, BP3, 91710 Vert-le Petit, France. Fax: 33164935266

Keywords: Ciliary beat frequency, increased pressure, nitric oxide

Received: May 181998

Accepted after revision November 301998
Mucociliary transport in the respiratory tract plays an important role in lung defence mechanisms. The two main components of the mucociliary apparatus, cilia and mucus, are exposed to environmental or toxic factors which can impair their structure and functions. The effects of various physical factors such as temperature, relative humidity and $\mathrm{pH}$ on mucociliary clearance, have been previously studied [1-3]. The respiratory epithelium covering upper and lower airways can also be submitted to pressure variations. These variations can be modest, such as in cough or assisted ventilation, or major, as in diving. The effects of increased pressure on tracheal mucus clearance have received little attention in the literature [4]. Pressure variations can act either on mucus properties and/or on ciliary motility. In order to test the direct effects of increased pressure on ciliary beat frequency (CBF), a series of in vitro experiments on guinea-pig tracheal rings were conducted. The data demonstrated that increased pressure caused marked enhancement in tracheal CBF. As the generation of nitric oxide by airways has been shown to be involved in the modulation of $\mathrm{CBF}[5,6]$, it was hypothesized that increased pressure could act on $\mathrm{CBF}$ via NO release. The effect of $N^{\mathrm{G}}$-nitro-L-arginine methylester (L-NAME), an inhibitor of NO synthase (NOS), on $\mathrm{CBF}$ enhancement induced by a pressure increase was therefore studied.

\section{Methods}

Ciliary beat frequency measurement

Ciliary beat frequencies were measured on guinea-pig tracheal rings immersed in Tyrode's solution (composition in $\mathrm{mM}: 139.2 \mathrm{NaCl} ; 2.7 \mathrm{KCl} ; 1.8 \mathrm{CaCl}_{2} ; 0.49 \mathrm{MgCl}_{2}$. $6 \mathrm{H}_{2} \mathrm{O} ; 0.4 \mathrm{NaH}_{2} \mathrm{PO}_{4} \cdot \mathrm{H}_{2} \mathrm{O} ; 5.5$ glucose; $11.9 \mathrm{NaHCO}_{3}, \mathrm{pH}$ 7.4). The $\mathrm{CBF}$ measurement system included a video camera (Sony, Paris, France) connected to the triocular head of an inverted phase contrast microscope (Nachet, Dijon, France) using a $\times 40$ objective enabling the image to be stored on videotape (Panasonic, Paris, France). Videotape sequences were analysed sequence by sequence, using automated images, according to the technique initially described by ZAHM et al. [7]. Briefly, the video output of the processor board was directed to a black and white monitor. The image was digitized by a digital signal processor board with 8 -bit greyscale and $512 \times 512$ pixel size. The software developed was driven by a PC computer. The region of interest was outlined by a graphical square with a size of $66 \times 66$ pixels positioned over a ciliated cell on the digitized image using the computer mouse. The sample area was $150 \mu \mathrm{m}^{2}$ and corresponded to a single ciliated cell area, including $\sim 200$ cilia. A fast Fourier transform (FFT) algorithm was used to analyse the brightness variations according to the method of COOLEY and TukEY [8]. From FFT analysis, the spectrum distribution of $\mathrm{CBF}$ was displayed on the computer monitor. For each spectrum, the mean value and standard deviation of the frequency was calculated and stored on the computer hard disk. Each measurement represents the mean value calculated from 15 different regions, randomly selected by pointing with the computer mouse.

\section{Pressure increase}

The pressure chamber was designed and built in the authors' institution. This chamber consisted of a solid metal block machined in a $70-\mathrm{mm}$ stainless steel circle. Its 
internal diameter was $28 \mathrm{~mm}$ and its height was $10 \mathrm{~mm}$. The lower and upper round glass cover slips were made from microscope slides (1 mm thick) for microscopic examination. Tests were performed to ensure that the pressure chamber was sufficiently robust to support a pressure of $200 \mathrm{kPa}$. Pressure was induced by a pressure regulator (Brooks, 8601D, New York, NY, USA) and was controlled with a pressure manometer (Bourdon, Paris, France).

A gas mixture with a high oxygen concentration was generated with an air/oxygen mixture (A01; Bennett, Los Angeles, CA, USA). Gas composition, especially oxygen pressure in the chamber, was determined from samples analysed with a blood gas analyser (ABL 300; Radiometer SA, Caen, France).

\section{Experimental protocol}

The experimental procedure and specific protocol were approved by the Committee on Animal Care of the authors' Institution. Male Hartley outbred guinea-pigs (Charles River, Saint Aubin Les Elbeuf, France) weighing 250-300 $\mathrm{g}$, housed at $22^{\circ} \mathrm{C}$ with food (UAR, Villemoisson, France) and water freely available, were used in this study. Guineapigs were anaesthetized with $50 \mathrm{mg} \cdot \mathrm{kg}$ body weight ${ }^{-1}$ i.p. of pentobarbital sodium and exsanguinated by severing the abdominal aorta. The thorax was opened and the trachea was immediately removed and sectioned in rings which were immersed in Tyrode's solution aerated with $95 \% \mathrm{O}_{2}$ and $5 \% \mathrm{CO}_{2}$ for $30 \mathrm{~min}$. Each experiment was performed on a group of six animals. Before all experiments, it was ensured that the CBF of a tracheal ring, immersed in the pressure chamber closed and maintained at atmospheric pressure, was not modified for $4 \mathrm{~h}$. As variations of $\mathrm{pH}$ and temperature are also known to modify $\mathrm{CBF}$, these two parameters were checked at the beginning and at the end of each experiment.

The influence of the pressure on CBF was determined by studying the course of the CBF of tracheal rings when the pressure was set at 25 and $100 \mathrm{kPa}$ for $150 \mathrm{~min}$. Reversibility was studied on the same tracheal rings after return to atmospheric pressure, either in the same solution or after washing in new Tyrode's solution. When pressure increases with a constant gas composition, the partial pressure of the various gases, especially oxygen, also increases. In another series of experiments, the respective effects of increasing pressure were therefore compared with the effects of increasing oxygen concentration, i.e. air at a pressure of $50 \mathrm{kPa}$ with a mixture containing $31 \%$ oxygen at atmospheric pressure $(\mathrm{n}=6)$.

Lastly, to demonstrate the pathway involved in CBF stimulation, the effects of L-NAME $\left(10^{-4} \mathrm{M}\right)$, an inhibitor of NOS, on CBF enhancement observed on a tracheal ring submitted to a pressure increase of $25 \mathrm{kPa}$ for $30 \mathrm{~min}$ were studied. The effects of L-arginine $\left(10^{-4} \mathrm{M}\right)$, a precursor of NO, were also studied on the same preparation. L-NAME or its solvent were added once the CBF stimulation was observed, by opening the chamber and so their effects were evaluated on preparations, just after return to atmospheric pressure. L-arginine or its solvent were added $15 \mathrm{~min}$ after the addition of L-NAME.

\section{Reagents}

L-NAME was obtained from Sigma (Saint Quentin Fallavier, France) and L-arginine was obtained from Bioblock (Illkirch, France). These compounds were dissolved in Tyrode's solution.

\section{Statistical analysis}

Data are expressed as mean \pm SEM. Results of the various experiments were compared using one way analysis of variance followed by a post hoc Bonferroni-Dunn test. A p-value $<0.05$ was considered to be statistically significant.

\section{Results}

\section{Influence of ambient pressure on ciliary beat frequency}

In order to evaluate the effects of pressure and the time course of this effect, two different levels of pressure were studied during a 150-min period. The effects observed at pressures of 25 and $100 \mathrm{kPa}$ were not significantly different (fig. 1). For each pressure value, an increase in $\mathrm{CBF}$, compared to control values, was demonstrated 30 min after the onset of the pressure increase (from $7.66 \pm 0.21 \mathrm{~Hz}$ to $8.32 \pm 0.27 \mathrm{~Hz}$ for $25 \mathrm{kPa}$ and from $7.49 \pm 0.15 \mathrm{~Hz}$ to $8.94 \pm 0.26 \mathrm{~Hz}$ for $100 \mathrm{kPa}, \mathrm{p}<0.05)$. A plateau was reached after $90 \mathrm{~min}(10.58 \pm 0.35 \mathrm{~Hz}$ for 25 $\mathrm{kPa}$ and $10.98 \pm 0.26 \mathrm{~Hz}$ for $100 \mathrm{kPa}$ ) and was maintained for $150 \mathrm{~min}$. CBF measured after $150 \mathrm{~min}$ at $25 \mathrm{kPa}$ was not modified after return to atmospheric pressure and persisted for $60 \mathrm{~min}$, whether the tracheal ring remained in the same Tyrode's solution $(10.51 \pm 0.39 \mathrm{~Hz}$ after 150 min at $25 \mathrm{kPa}$ and $10.57 \pm 0.48 \mathrm{~Hz}, 60$ min later) or was placed in a new solution of the same composition $(10.72 \pm 0.47 \mathrm{~Hz}$ after $150 \mathrm{~min}$ at $25 \mathrm{kPa}$ and $10.35 \pm 0.22$ $\mathrm{Hz}, 60 \mathrm{~min}$ later) (fig. 2).

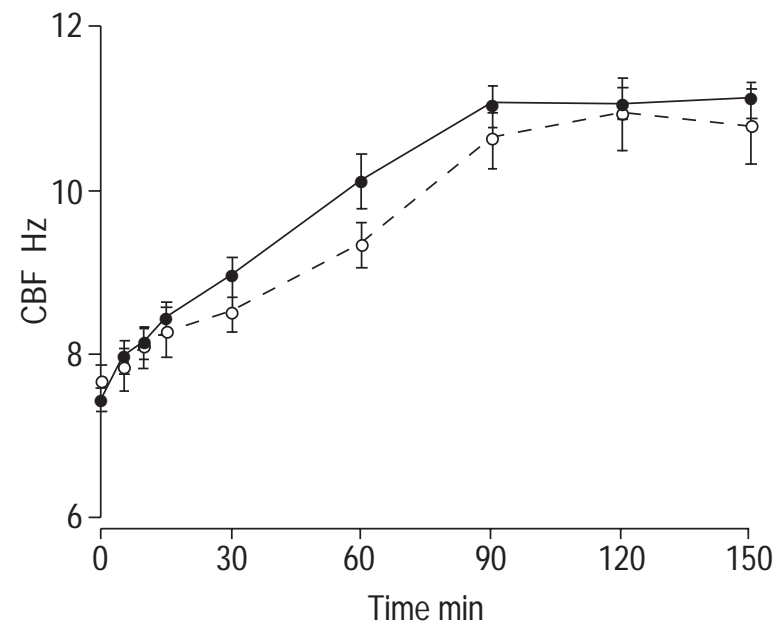

Fig. 1. - Comparative effect of a pressure increase of $25 \mathrm{kPa}\left(--\right.$ - $^{-}$and $100 \mathrm{kPa}(-)$ on ciliary beat frequency $(\mathrm{CBF})$. Values are mean \pm SEM. After $30 \mathrm{~min}$, the increase in $\mathrm{CBF}$ was significant for the two pressure levels compared to control values $(\mathrm{p}<0.05$, Bonferroni-Dunn test, $\mathrm{n}=6)$. 


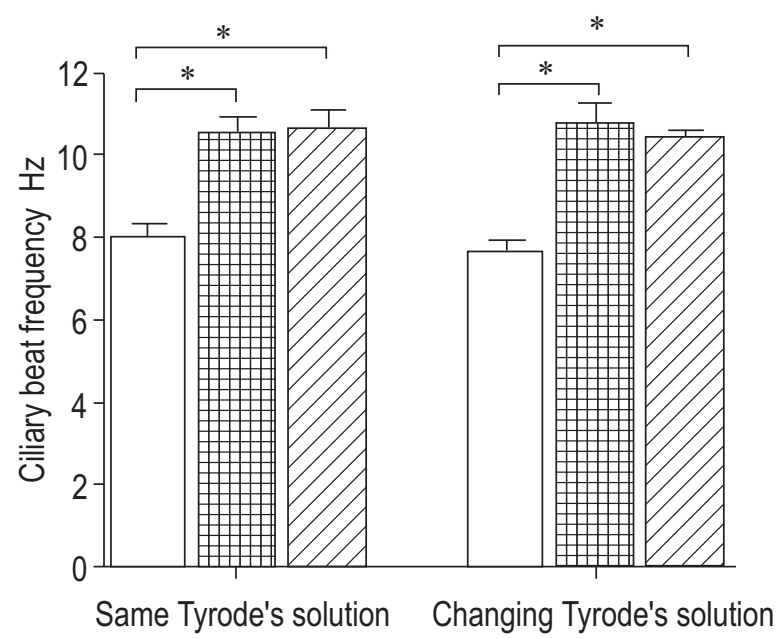

Fig. 2. - The course of a $25 \mathrm{kPa}$ pressure increase. Values are mean \pm SEM. The tracheal ring was either maintained in the same Tyrode's solution when returning atmospheric pressure or the solution was changed after $150 \mathrm{~min}$, i.e. when returning at atmospheric pressure. No reversibility was observed in either situation. $\square$ : control; 曲: $25 \mathrm{kPa}$ for 150 min; $\mathbb{Z}: 25 \mathrm{kPa}$ for $150 \mathrm{~min}$ followed by $0 \mathrm{kPa}$ for $60 \mathrm{~min}$. $*$ : $\mathrm{p}<0.05$, Bonferroni-Dunn test, $\mathrm{n}=6$.

\section{Respective effects of pressure and oxygen tension}

The increase in CBF of tracheal rings submitted to a pressure of $50 \mathrm{kPa}$ for $60 \mathrm{~min}$ was significantly greater than the increase in CBF observed in tracheal rings of the same trachea placed in a gas mixture containing $31 \% \mathrm{O}_{2}$ at atmospheric pressure (from $8.53 \pm 0.46$ to $10.40 \pm 0.63 \mathrm{~Hz}$ and from $8.85 \pm 0.51$ to $11.89 \pm 0.60 \mathrm{~Hz}$, respectively, $\mathrm{p}<0.05)$.

\section{Effect of nitric oxide synthase inhibitor}

The CBF of tracheal rings exposed to a pressure of 25 $\mathrm{kPa}$ increased from $6.76 \pm 0.24 \mathrm{~Hz}$ to $8.16 \pm 0.49 \mathrm{~Hz}$ ( $\mathrm{p}<$

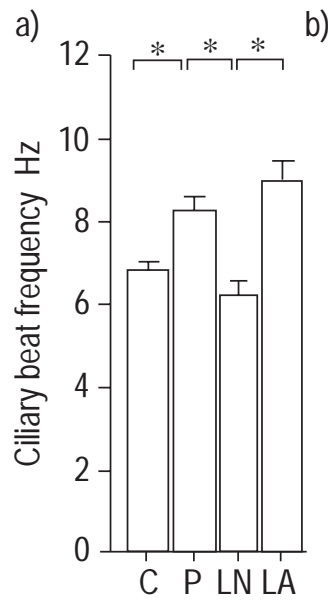

b)
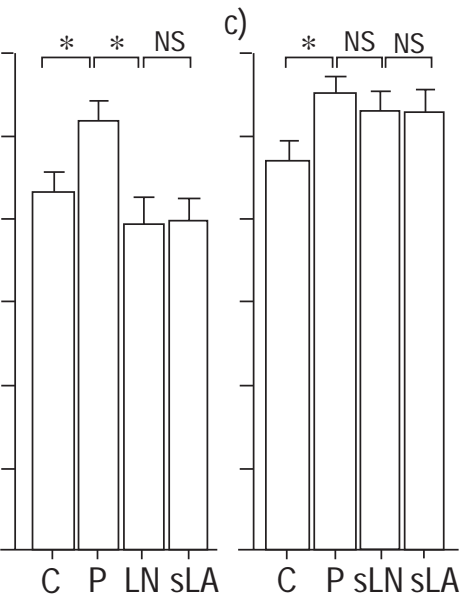

Fig. 3. - The effect of nitric oxide synthase inhibitor. Values are mean \pm SEM. a) $N^{\mathrm{G}}$-nitro-L-arginine methylester (LN) inhibits ciliary beat frequency $(\mathrm{CBF})$ enhancement observed after a pressure increase of $25 \mathrm{kPa}$ for 30 min and L-arginine (LA) inhibits the effects of LN; b) the solvent of LA (sLA) did not inhibit the effects of LN; and c) the solvent of LN (sLN) and sLA had no effect on the CBF enhancement observed after a pressure increase of $25 \mathrm{kPa}$. C: control; P: $25 \mathrm{kPa}$ for $30 \mathrm{~min} .{ }^{*}: \mathrm{p}<0.05$, Bonferroni-Dunn test, $\mathrm{n}=6$.
0.05). Addition of L-NAME induced a decrease in CBF to $6.19 \pm 0.35 \mathrm{~Hz}$ within $5 \mathrm{~min}(\mathrm{p}<0.05)$ (fig. 3). Addition of $\mathrm{L}$-arginine to these same tracheal rings induced an increase in $\mathrm{CBF}$ to $8.9 \pm 0.52 \mathrm{~Hz}$, within $5 \mathrm{~min}(\mathrm{p}<0.05)$. For these two products, solvents alone did not induce any significant variation of CBF. Addition of L-NAME or Larginine alone did not induce any significant variations of basal CBF (data not shown).

\section{Discussion}

These results demonstrate that a pressure increase applied to guinea-pig tracheal rings in vitro induces enhancement of $\mathrm{CBF}$ and that $\mathrm{NO}$ generation may be involved in this ciliary stimulation.

Airways can be exposed to environmental physicochemical factors. Variations in these factors can modify airway mucociliary function [3]. The influence of some of these factors such as temperature, humidity and $\mathrm{pH}$ on mucus transport has been previously studied [1-3]. As mucociliary clearance depends on interactions between ciliary activity and mucus properties, effects of modifications of these physical factors have been separately studied on each of these two components. The effects of changing temperature, $\mathrm{pH}$ and humidity on $\mathrm{CBF}$ have consequently been studied in vivo and in vitro $[9,10]$. For these parameters, a good correlation was found between the effects observed on mucociliary clearance and the effects observed on CBF [4]. To the authors' knowledge, the direct effect of increasing pressure on $\mathrm{CBF}$ has not been studied.

The present results demonstrate that an increase in pressure can enhance $\mathrm{CBF}$. When pressure exceeds $25 \mathrm{kPa}$, a significant enhancement of CBF is observed within 30 min, a plateau is reached $90 \mathrm{~min}$ after the onset of the pressure increase and $\mathrm{CBF}$ remains relatively constant for at least $150 \mathrm{~min}$. Enhancement of CBF is not reversible after returning to atmospheric pressure whether the tracheal ring remains in the same solution or is placed in a new physiological saline solution. This result suggests an intrinsic mechanism.

In the experiments performed with room air, when pressure increased, with constant inspiratory oxygen fraction $\left(F \mathrm{I}, \mathrm{O}_{2}\right)$, oxygen tension $\left(\mathrm{PO}_{2}=\right.$ pressure $\left.\times F \mathrm{I}, \mathrm{O}_{2}\right)$ also increased. Several studies have dealt with the effect of hyperoxia on CBF [4]. As HARRISON et al. [11] demonstrated that short-term local hyperoxia could stimulate CBF, the respective effects on $\mathrm{CBF}$ of an increase in pressure and an increase in $\mathrm{PO}_{2}$ were determined. In this way, the effect observed with air $\left(\sim 21 \% \mathrm{O}_{2}\right)$ at a pressure of $50 \mathrm{kPa}$ was compared to the effect observed with a mixture containing $31 \% \mathrm{O}_{2}$ at atmospheric pressure, i.e. two conditions with the same equivalent $P_{2}(\sim 33 \mathrm{kPa})$. The enhancement of $\mathrm{CBF}$ observed with increased pressure was significantly greater than that observed with hyperoxia alone. This result indicates that an important part of the enhancement of $\mathrm{CBF}$ observed in response to a pressure increase is owing to the increase in $\mathrm{PO}_{2}$ associated with this pressure increase and another part is directly due to the pressure per se. This result is in accordance with the classical observation that ciliated cells are mechanosensitive [12]. When the cell surfaces or cilia of cultured ciliated epithelial cells from rabbit 
trachea are stimulated with a small glass microneedle, $\mathrm{CBF}$ increases [13]. However, in this case, in contrast to the response observed in the present study, SANDERSON and DIRKSEN [13] demonstrated that the CBF increases within milliseconds to seconds of the stimulus and this response is calcium dependent.

Many mechanisms are involved in CBF modulation. Among the mediators that are known to upregulate CBF, $\mathrm{NO}$, a multipurpose messenger molecule largely present in the airways $[14,15]$, has been shown to enhance CBF in epithelial cells in culture, in response to isoproterenol or salbutamol $[5,6]$. Based on the time-course of the increase in CBF observed in the present study, occurring within $30 \mathrm{~min}$ and lasting for longer than $60 \mathrm{~min}$, this effect resembles that observed with isoproterenol. It was therefore hypothesized that NO could also be involved in the effect of high ambient pressure on CBF. These results support this hypothesis. This conclusion is based on the following observations: 1) the NOS inhibitor, L-NAME, rapidly slowed $\mathrm{CBF}$ stimulation induced by the pressure increase; 2) this effect was reversed by L-arginine, a precursor of $\mathrm{NO} ; 3$ ) solvents of these products did not have any effect per se; and 4) L-NAME had no significant effect on the basal CBF. The exact pathways of transduction involved in the NO-induced increase in ciliary motility have not been completely elucidated. Epithelial cells contain large amounts of constitutive NOS (cNOS), as demonstrated on histological sections by immunostaining in previous studies [14]. However, they are capable of expressing inducible NOS (iNOS). Based on the time-course of the effect, it is more probable that the pressure increase may activate iNOS.

An increased pressure along the airways can be observed in cough, assisted ventilation or diving. Pressures generated in cough and assisted ventilation are $\sim 100$ $\mathrm{cmH}_{2} \mathrm{O}$, i.e. $10 \mathrm{kPa}$, for brief periods. Only a part of these pressures is dissipated in shearing forces at the wall, i.e. epithelial cells. In cough or assisted ventilation, the direct effects of pressure on epithelial cell functions are probably limited. In diving, a significant hydrostatic pressure is inseparable from the aquatic environment in which the ambient pressure increases by $\sim 10 \mathrm{kPa}$ for a depth of $1 \mathrm{~m}$. Pressures observed between 1 and $10 \mathrm{~m}$ in depth which represent the depths of most diving expeditions, are between 10 and $100 \mathrm{kPa}$. These pressures are in the range of the pressures applied in this study and their time of application can be as long as in this experiment. These results suggest that pressures applied on epithelial cells during diving may influence ciliary beat.

This in vitro study demonstrated that an increased pressure may improve ciliary beat, possibly via a mech- anism involving nitric oxide. Other studies are needed to evaluate the effect of pressure on mucus properties, the other major component of mucociliary clearance.

\section{References}

1. Mercke U, Hakansson CH, Toremalm NG. The influence of temperature on mucociliary activity. Temperature range 20-40 ${ }^{\circ}$ C. Acta Otolaryagol 1974; 78: 444-450.

2. Mercke U, Toremalm NG. Air humidity and mucociliary clearance. Ann Otol Rhinol Laryngol 1976; 85: 32-37.

3. Wanner A. Clinical aspects of mucociliary transport. Am Rev Respir Dis 1977; 116: 73-125.

4. Wanner A, Salathé M, O'Riordan TG. Mucociliary clearance in the airways. Am J Respir Crit Care Med 1996; 154: 1868-1902.

5. Jain B, Rubinstein RA, Robbins KL, Leise KL, Sisson JH. Modulation of airway epithelial cell ciliary beat frequency by nitric oxide. Biochem Biophys Res Commun 1993; 191: 83-88.

6. Tamaoki J, Chiyotani A, Kondo M, Konno K. Role of NO generation in $\beta$-adrenoceptor-mediated stimulation of rabbit airway ciliary motility. Am J Physiol 1995; 268 : C1342-C1347.

7. Zahm JM, Pierrot D, Hinnrasky J, Fuchey C, Chevillard M, Puchelle E. Functional activity of ciliated outgrowths from cultured human nasal and tracheal epithelia. Biorheology 1990; 27: 559-565.

8. Cooley JW, Tukey JW. An algorithm for the machine calculation of complex Fourier series. Math Comput 1965; 19: 297-301.

9. Luk CK, Dulfano MJ. Effect of $\mathrm{pH}$, viscosity and ionic strength on ciliary beating frequency of human bronchial explants. Clin Sci 1983; 64: 449-451.

10. Ingels KJAO, Kortmann MJW, Nijziel MR, Graamans K, Huizing EH. Factors influencing ciliary beat measurements. Rhinology 1991; 29: 17-26.

11. Harrison RA, Wong LB, Yeates DB. Short-term interaction of airway and tissue oxygen tensions on ciliary beat frequency in dogs. Am Rev Respir Dis 1992; 146: 141-147.

12. Satir P, Sleigh MA. The physiology of cilia and mucociliary interactions. Annu Rev Physiol 1990; 52: 137-155.

13. Sanderson MJ, Dirksen ER. Mechanosensitivity of cultured ciliated cells from the mammalian respiratory tract: implications for the regulation of mucociliary clearance. Proc Natl Acad Sci USA 1986; 83: 7302-7306.

14. Gaston B, Drazen JM, Loscalzo J, Stamler JS. The biology of nitrogen oxides in the airways. Am J Respir Crit Care Med 1994; 149: 538-551.

15. Adnot S, Raffestin B, Eddahibi S. NO in the lung. Respir Physiol 1995; 101: 109-120. 